This is a post-peer-review, pre-copyedit version of an article published in Blurring the Boundaries Through Digital Innovation, part of the Lecture Notes in Information Systems and Organisation book series (LNISO, volume 19). The final authenticated version is available online at: https://doi.org/10.1007/978-3-319-38974-5_16

\title{
Power to the (shopping) people! Changing traditional customer-vendor interaction in online markets by ICT-enabled "group buying"
}

\author{
Andreas Mladenow ${ }^{1, *}$, Christine Bauer ${ }^{2}$, and Christine Strauss ${ }^{1}$ \\ ${ }^{1}$ University of Vienna, Department of eBusiness, Vienna, Austria \\ \{andreas.mladenow, christine.strauss\}@univie.ac.at \\ ${ }^{2}$ University of Cologne, Department of Information Systems and Information Management, \\ Cologne, Germany \\ bauer@wim. uni-koeln. de
}

\begin{abstract}
Information and communication technologies (ICT) are enablers for cooperative and collective online shopping. This novel phenomenon is also known under the terms "group buying" and "collective buying" and can be found in business-to-business (B2B) contexts as well as in business-to-consumer (B2C) shopping transactions. We investigate recent developments regarding enablers and inhibitors of ICT-based group buying concepts in various markets. In this paper, we perform a thorough analysis of group buying approaches with the intent to explain the evolution, developments, and changes of online group shopping variants. We provide an overview of approaches and derived variants of the online group buying concept highlighted with selected real-world application examples. A detailed SWOT analysis (strengths, weaknesses, opportunities, and threats) for each of the two dominant approaches (top-down and bottom-up) represents the core contribution of the paper and may build the basis for the development and improvement of future business models in the field.
\end{abstract}

Keywords: Online Group Buying; Crowd-Shopping; Social Shopping; Interaction of Actors; Bottom-Up; Top-Down; Change Processes; ICT-enabled Business Models; Crowdsourcing; Collaboration

\section{Introduction}

Information and communication technologies (ICT) are enablers that bring together consumers with similar interests around the world. Thereby, the vast availability of such technologies also stimulates cooperative and collective online shopping [1]: consumers perform shopping in groups, whereby they either act collectively or in assigned roles. This phenomenon is referred to as "group buying" and "collective buying" $[2,3]$. Group buying is not restricted to the online setting; however, ICT is a strong enabler supporting and improving the entire process of buying, including group forming, discussion among group participants, bargaining with vendors, decision making (e.g., selection of vendor, selection of product or service), post-purchase services, etc. [3, 4].

Recently, online group buying has become a widespread shopping alternative worldwide and numerous online platforms have emerged that support all activities 


\section{PRE-PRINT VERSION}

Mladenow, Andreas, Bauer, Christine, \& Strauss, Christine (2016). Power to the (Shopping) People! Changing Traditional Customer-Vendor Interaction in Online Markets by ICT-Enabled “Group Buying”. In D'Ascenzo, Fabrizio, Magni, Massimo, Lazazzara, Alessandra, \& Za, Stefano (eds.), Blurring the Boundaries through Digital Innovation: Individual, Organizational, and Societal Challenges. Lecture Notes in Information Systems and Organisation (LNISO), Volume 19, pp 203-213. Cham, Switzerland: Springer. DOI: 10.1007/978-3-319-38974-5_16

This is a post-peer-review, pre-copyedit version of an article published in Blurring the Boundaries Through Digital Innovation, part of the Lecture Notes in Information Systems and Organisation book series (LNISO, volume 19). The final authenticated version is available online at: https://doi.org/10.1007/978-3-319-38974-5_16

involved in group buying (e.g., LivingSocial.com, Groupon.com, Teambuy.com.cn, Dianpin.com, Meituan.com). Besides the emergence of online group buying platforms that are operated by intermediaries (top-down approach), ICT also enable users to form and self-manage a cooperative group via various communication channels (bottom-up approach) [5].

Considering the leading online group buying platforms in various markets and/or countries, it can be observed that the success of the different approaches to online group buying varies $[3,6]$. Furthermore, the online group buying phenomenon has developed into diverse directions. The main questions are: What are the success factors for online group buying business models? And what are the influencing factors that drive the differed developments and changes in the various markets?

Against these major research questions of our ongoing research, the present paper engages with a thorough analysis of the top-down and bottom-up business models of online group buying with different pricing models covering both, fixed as well as dynamic pricing mechanisms. For instance, a group buying platform may facilitate communication between the participants and provide all necessary communication functionalities for the involved stakeholders. Each individual customer or consumer has his/her own notion of the maximum amount he/she is willing to pay for the specific product or service in which every member of the collective is interested. This personal reserve price serves as a benchmark of whether the price offered is perceived as too cheap or too expensive. The higher the difference between final and reserve price, the more satisfied the consumer will be. Another key factor that may vary between consumers covers the time span that he/she is willing to wait for the purchase of the product or service. If it takes too long for the consumer to receive a product as a member of a group buying purchase, he/she might choose to join another collective for which the transaction finalizes earlier or even buy the product on his/her own directly from a vendor at retail price.

This paper analyses recent developments regarding enablers and inhibitors of ICTbased group buying approaches in different markets. After outlining the theoretical background of our work in Section 2, we will perform a SWOT (strengths, weaknesses, opportunities, and threats) analysis in Section 3 that will allow for discussing the enablers and the inhibitors of ICT in the different approaches to online group buying in Section 4. In this final Section, we also conclude with a brief summary of our work and point to future research opportunities.

\section{Theoretical Background}

In this section, we first provide details on group buying; then we continue with outlining different online group buying approaches as currently observed on the market.

\subsection{Group Buying}

"Group buying" or "collective buying" is a shopping strategy in B2C (business-toconsumer) as well as B2B (business-to-business) interactions between vendors and purchasers in which consumers form a collective. In our work, we focus on the B2C setting. With a group buying strategy consumers aim at obtaining price reductions or better conditions for purchases than they would obtain as individuals [2, 7]. Volume discounts and the opportunity to obtain additional services or customized package solutions are main motivators for consumers to engage in group buying [8,9]. For 


\section{PRE-PRINT VERSION}

Mladenow, Andreas, Bauer, Christine, \& Strauss, Christine (2016). Power to the (Shopping) People! Changing Traditional Customer-Vendor Interaction in Online Markets by ICT-Enabled “Group Buying”. In D'Ascenzo, Fabrizio, Magni, Massimo, Lazazzara, Alessandra, \& Za, Stefano (eds.), Blurring the Boundaries through Digital Innovation: Individual, Organizational, and Societal Challenges. Lecture Notes in Information Systems and Organisation (LNISO), Volume 19, pp 203-213. Cham, Switzerland: Springer. DOI: 10.1007/978-3-319-38974-5_16

This is a post-peer-review, pre-copyedit version of an article published in Blurring the Boundaries Through Digital Innovation, part of the Lecture Notes in Information Systems and Organisation book series (LNISO, volume 19). The final authenticated version is available online at: https://doi.org/10.1007/978-3-319-38974-5_16

instance, when groups buy higher quantities of items, they may bargain with the vendor to obtain volume discounts $[5,6]$. Furthermore, a collective, which is willing to buy a high quantity of the same product or service, has increased bargaining power; consequently the group may negotiate on better conditions, additional services, or customized package solutions [10]. In addition, there is an incentive for uninformed individuals to cooperate with intermediaries as well as knowledgeable consumers that have a better understanding of the market and good negotiation skills [7].

Besides consumers, vendors equally benefit from group buying [11]. One advantage for vendors lies in the potentially increased sales, which they may realize due to a high(er) demand generated by collective buyers [12]. As a result, the vendor may generate profits despite lower prices compared to traditional retailing strategies due to the quantities sold [12]. Higher sales quantities lead to higher demand between vendor and wholesaler or supplier, which raises the vendors' negotiating power in his interaction with his supplier. Higher sales quantities also result in financial flexibility, as cash flow and, thus, liquidity might increase significantly. Furthermore, large batches of goods (sales and purchase) lead to a reduction of proportional fixed cost per unit. From a vendor's perspective, a deal with a group buying collective is typically cost-effective: since they do not have to deal with each of the consumers individually. Consequently, group buying transactions involve lower communication and bargaining costs [13].

While the online group buying phenomenon has flourished worldwide, it can be observed that the adopted business models have developed into diverse directions across the markets. The major two online group buying approaches are described in the next subsection.

\subsection{Online Group Buying Approaches}

The major two types of online group buying approaches are the top-down approach and the bottom-up based approach. Based on these two generic model types several derivative variants have developed.

Regarding the top-down group buying approach, the shopping process is not initiated by potential consumers, but by the platform providers themselves [5]. There are two variants: in the dynamic price-level variant, the vendor provides a prepackaged offer, which consumers may either accept or decline as is within the offer's validity period. Thus, the vendor does not warrant the consumers any negotiation possibilities. The rationale behind this group buying variant that offers prepackaged "deals" is the following: the more users who are willing to buy a particular product or service, the lower the price. Example platforms are Mercata.com, LetsBuyIt.com, and Mobshop.com that were already launched in the 1990s. In early 2008, a second variant of the top-down approach was initiated by Groupon.com [14, 15]. The prepackaged "deals" (typically special discounts) have a fixed price; a minimum number of required customers that has to be exceeded for the respective offer within a certain time period (typically a day) in order to obtain the discount, which may be redeemed after payment $[16,1]$.

An example for the bottom-up approach is a concept that allows for so-called group buying discounts, i.e., quantity discounts [5]. In the dynamic price level variant, the crowd formation is the first process phase; the crowd searches for potential merchants offer; then, a selected group representative negotiates with the merchant. This phase may also take place in the merchant's premises. The group discusses the available deals and, finally, the merchant's offer might be accepted to the agreed conditions. 


\section{PRE-PRINT VERSION}

Mladenow, Andreas, Bauer, Christine, \& Strauss, Christine (2016). Power to the (Shopping) People! Changing Traditional Customer-Vendor Interaction in Online Markets by ICT-Enabled “Group Buying”. In D'Ascenzo, Fabrizio, Magni, Massimo, Lazazzara, Alessandra, \& Za, Stefano (eds.), Blurring the Boundaries through Digital Innovation: Individual, Organizational, and Societal Challenges. Lecture Notes in Information Systems and Organisation (LNISO), Volume 19, pp 203-213. Cham, Switzerland: Springer. DOI: 10.1007/978-3-319-38974-5_16

This is a post-peer-review, pre-copyedit version of an article published in Blurring the Boundaries Through Digital Innovation, part of the Lecture Notes in Information Systems and Organisation book series (LNISO, volume 19). The final authenticated version is available online at: https://doi.org/10.1007/978-3-319-38974-5_16

This variant of the bottom-up approach is particularly popular in Asia (e.g., TeamBuy.com.cn, liba.com) [17, 2, 5]. It brings together consumers who intend to buy a specific product or service. The crowd participants may enjoy discounted pricing through collective bargaining. They have the opportunity to meet on an online forum or on specific websites, which might speed up the process of crowd formation. Another variant is the bottom-up approach with fixed price level.

Figure 1 provides an overview of approaches and variants of online group buying and lists some example applications (cf. Fig. 1).

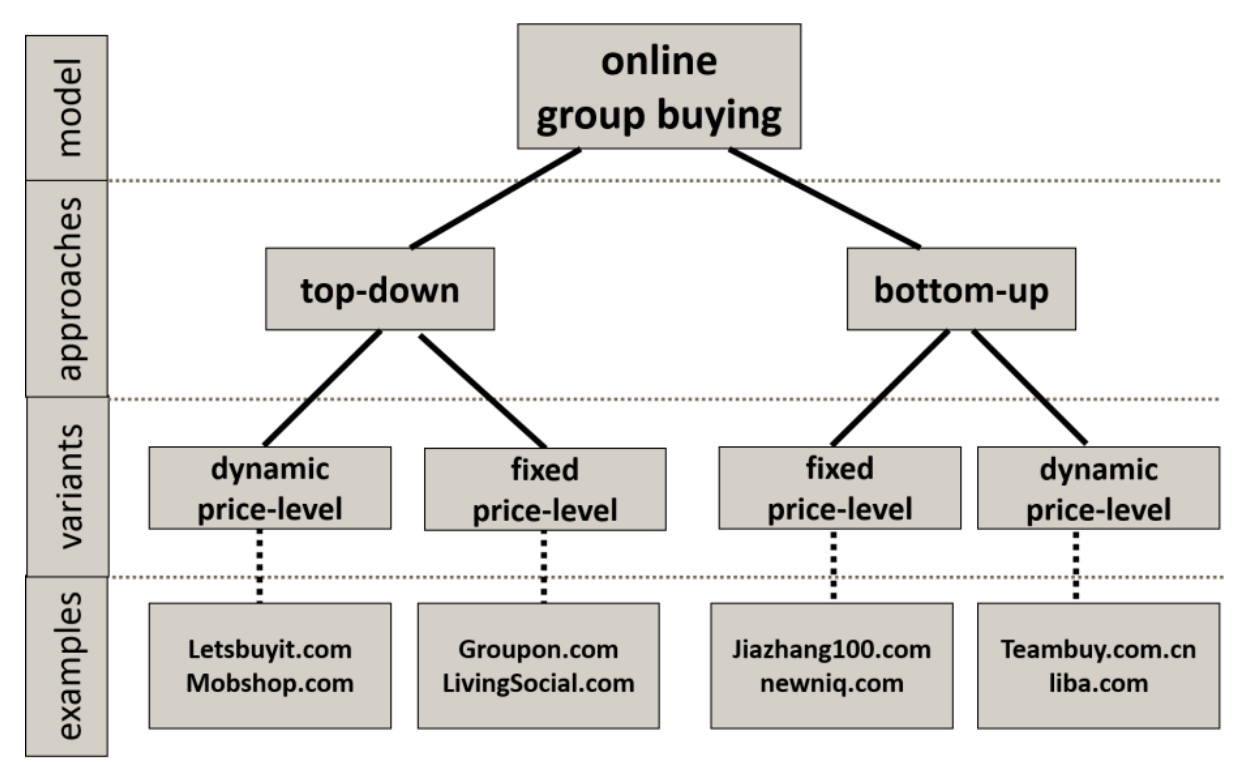

Figure 1: Overview of approaches, variants, and application examples of the group buying concept

\section{Enablers and Inhibitors of Online Group Buying}

Web-based interaction between consumers provides new opportunities for innovative forms of cooperation between customers and suppliers [18, 19], which go in line with the social shopping experience that is recently emphasized in practice. Having extensive market knowledge is a key to success for companies offering demand-oriented services [20]. Thereby, web-companies may not only gain an advantage over competitors in the long term but they might also achieve a quality advantage [21].

The SWOT matrix of the dominant top-down approach is depicted in Table 1. The major platform providers using this approach typically provide a broad portfolio of offerings with additional services. A specific strength of Groupon.com and TeamBuy.com.cn lies in the good navigability of the platform thanks to a good user interface. From the provider's perspective, the high number of non-redeemers is 


\section{PRE-PRINT VERSION}

Mladenow, Andreas, Bauer, Christine, \& Strauss, Christine (2016). Power to the (Shopping) People! Changing Traditional Customer-Vendor Interaction in Online Markets by ICT-Enabled “Group Buying”. In D'Ascenzo, Fabrizio, Magni, Massimo, Lazazzara, Alessandra, \& Za, Stefano (eds.), Blurring the Boundaries through Digital Innovation: Individual, Organizational, and Societal Challenges. Lecture Notes in Information Systems and Organisation (LNISO), Volume 19, pp 203-213. Cham, Switzerland: Springer. DOI: 10.1007/978-3-319-38974-5_16

This is a post-peer-review, pre-copyedit version of an article published in Blurring the Boundaries Through Digital Innovation, part of the Lecture Notes in Information Systems and Organisation book series (LNISO, volume 19). The final authenticated version is available online at: https://doi.org/10.1007/978-3-319-38974-5_16

advantageous, as it allows for higher profits [22]. As the platforms are typically large, economies of scale can easily be accomplished. A remarkable strength of the platforms lies also in the fact that they localize their products and services and provide a recognizable share of localized offers in their portfolio. As the top-down approach does not require user interaction, the platforms do not have to support and facilitate interaction among users. The low interaction of consumers also means that the consumers rarely influence each other, which is beneficial for the provider in terms of achieved profits.

A weakness of the concept lies in the low price margins that may be achieved. For the suppliers the transactions are on a wide scale not profitable. Accordingly, the approach may rather be considered as a marketing tool. A challenge for platform providers is to keep participating supplying companies, since their participation may not be profitable for them. When acting on different markets, the offer has to be adapted to every market, which includes high evaluation and transaction costs. The localization of offers therefore puts further burden on the platform providers. A further weakness can be ascribed to the broad mass of suppliers on the platforms. First, there may be quality issues or at least large quality differences. Second, there is hardly any differentiation in the supply from competing platforms. In addition, there are low switching costs for consumers, as they may switch to another provider by the click of a button. Furthermore, although the group buying concept would allow for a social shopping experience, the top-down approach does not exploit this capability as low interaction among the consumers is involved.

The opportunities for platform providers taking a top-down approach to group buying are versatile. Investing in additional channels such as in applications for mobile devices would be an asset. Offering a(n) (even) broader portfolio of products and (additional) services could be a further opportunity. Allowing participating supplier companies to have their own branding could be another driver for potential market growth. Addressing the weakness of low switching-costs for customers, targeted offers could strengthen customer loyalty by rewarding repeated purchases. Furthermore, the way that suppliers act, strongly influences a platform's reputation; relationship guidelines for such partner companies may positively impact the consumers' perception of the platform. Particularly with respect for the return business, such guidelines appear advantageous.

A present threat for platform providers is the tight competition in the field. The low entry barriers into the market for new companies intensify this threat. Potential bad user reviews and evaluations may cause consumers to switch to other, similar platforms [23, 24]. The strong dependency on its suppliers is also affected by the calculations performed by the latter; if calculations concerning quantities are not well elaborated, this may negatively impact the platforms reputation in two ways; first, suppliers that overestimate the (marginal) profits may not feel as equality treated partners; second, if a supplier cannot provide the quantities sold due to capacity problems may disappoint consumers. 


\section{PRE-PRINT VERSION}

Mladenow, Andreas, Bauer, Christine, \& Strauss, Christine (2016). Power to the (Shopping) People! Changing Traditional Customer-Vendor Interaction in Online Markets by ICT-Enabled “Group Buying”. In D'Ascenzo, Fabrizio, Magni, Massimo, Lazazzara, Alessandra, \& Za, Stefano (eds.), Blurring the Boundaries through Digital Innovation: Individual, Organizational, and Societal Challenges. Lecture Notes in Information Systems and Organisation (LNISO), Volume 19, pp 203-213. Cham, Switzerland: Springer. DOI: 10.1007/978-3-319-38974-5_16

This is a post-peer-review, pre-copyedit version of an article published in Blurring the Boundaries Through Digital Innovation, part of the Lecture Notes in Information Systems and Organisation book series (LNISO, volume 19). The final authenticated version is available online at: https://doi.org/10.1007/978-3-319-38974-5_16

Table 1. SWOT Analysis of the top-down group buying approach

\begin{tabular}{|c|c|}
\hline $\begin{array}{l}\text { Strengths } \\
\text { - } \text { broad portfolio of offerings } \\
\text { - good additional services } \\
\text { - good navigation / user interface } \\
\text { - high number of non-redeemers } \\
\text { - economies of scale } \\
\text { - localized offers } \\
\text { - low interaction and influence among } \\
\text { consumers }\end{array}$ & $\begin{array}{l}\text { Weaknesses } \\
\text { - low price margins } \\
\text { - transactions not profitable for } \\
\text { suppliers } \\
\text { - dependent on the offers by the } \\
\text { suppliers } \\
\text { - offer has to be adapted to every } \\
\text { market (high evaluation and } \\
\text { transaction costs) } \\
\text { - broad mass of suppliers are on the } \\
\text { platform } \\
\text { - no differentiation from competing } \\
\text { - low switching costs for consumers } \\
\text { low social shopping experience for } \\
\text { consumers }\end{array}$ \\
\hline $\begin{array}{l}\text { Opportunities } \\
\text { - improvement of apps for mobile } \\
\text { devices } \\
\text { - investing in broader portfolio } \\
\text { - branding for companies/suppliers } \\
\text { - entry in new markets (e.g., Eastern } \\
\text { Europe) } \\
\text { - targeted offers for customer loyalty } \\
\text { - auction system } \\
\text { - relationship guidelines for partners for } \\
\text { return business }\end{array}$ & $\begin{array}{l}\text { Threats } \\
\text { - tight competition } \\
\text { - low entry barriers into market for new } \\
\text { companies } \\
\text { - potential bad reviews/evaluations } \\
\text { - high number of redeemers } \\
\text { - bad calculations by suppliers may lead } \\
\text { to bad reputation of platform }\end{array}$ \\
\hline
\end{tabular}




\section{PRE-PRINT VERSION}

Mladenow, Andreas, Bauer, Christine, \& Strauss, Christine (2016). Power to the (Shopping) People! Changing Traditional Customer-Vendor Interaction in Online Markets by ICT-Enabled “Group Buying”. In D'Ascenzo, Fabrizio, Magni, Massimo, Lazazzara, Alessandra, \& Za, Stefano (eds.), Blurring the Boundaries through Digital Innovation: Individual, Organizational, and Societal Challenges. Lecture Notes in Information Systems and Organisation (LNISO), Volume 19, pp 203-213. Cham, Switzerland: Springer. DOI: 10.1007/978-3-319-38974-5_16

This is a post-peer-review, pre-copyedit version of an article published in Blurring the Boundaries Through Digital Innovation, part of the Lecture Notes in Information Systems and Organisation book series (LNISO, volume 19). The final authenticated version is available online at: https://doi.org/10.1007/978-3-319-38974-5_16

Table 2. SWOT Analysis of the bottom-up group buying approach

\begin{tabular}{|c|c|}
\hline $\begin{array}{l}\text { Strengths } \\
\text { - revenue (advertising channel) } \\
\text { - economies of scale } \\
\text { - high social shopping experience for } \\
\text { consumers } \\
\text { - good navigation / user interface } \\
\text { - broad portfolio of offerings by } \\
\text { - vendors } \\
\text { - } \text { localized offers } \\
\text { good additional service }\end{array}$ & $\begin{array}{l}\text { Weaknesses } \\
\text { - difficult to determine the suitable } \\
\text { waiting time } \\
\text { - insecurities concerning participating } \\
\text { consumers' purchase intention and } \\
\text { perceived obligation to purchase } \\
\text { - no income for transactions } \\
\text { - low switching costs for consumers } \\
\text { - highly dependent on the offers by the } \\
\text { - suppliers } \\
\text { - offer has to be adapted to every } \\
\text { market (high evaluation and } \\
\text { transaction costs) } \\
\text { - not applicable in many countries } \\
\text { - no differentiation from competing } \\
\text { platform }\end{array}$ \\
\hline $\begin{array}{l}\text { Opportunities } \\
\text { - improvement of apps for mobile } \\
\text { devices } \\
\text { - investing in additional services } \\
\text { - branding for companies/suppliers } \\
\text { - targeted offers for customer loyalty } \\
\text { - relationship guidelines for partners for } \\
\text { return business }\end{array}$ & $\begin{array}{l}\text { Threats } \\
\text { - tight competition } \\
\text { - low entry barriers into market for new } \\
\text { companies } \\
\text { - negative word-of-mouth }\end{array}$ \\
\hline
\end{tabular}

The waiting time until the ultimate purchase transaction represents a central challenge. Waiting time refers to the period in which the group is waiting for further growth in terms of group members, in order to generate higher demand and hence to achieve a higher order volume. The higher the number of orders within the crowd, the higher are the benefits from economies of scale (up to a certain limit) $[25,26,27,28$, 29 ] and the higher is thus also the quantity discount offered by the service provider to group members. However, this causes a dilemma that, for instance, the intermediary is confronted with when it comes to waiting time: on the one hand, a longer waiting period leads to a higher order volume and thus higher discounts; on the other hand, by waiting too long, the patience of the participants is challenged. As a consequence, if the waiting time is too long, some potential customers might drop out, as they are not willing to wait any longer. Therefore waiting causes a degree of uncertainty affecting the result of the entire crowd shopping project. The task of the crowd manager is, in this case, to analyse the market and to estimate a suitable waiting time for the specific situation (including product or service, market situation, already received offers, etc.) in order to find a good balance between a sufficiently large quantity of orders and a timely date of purchase or auction. Another challenge arising from implementing the crowd shopping concept as bottom-up instrument is that of ensuring that all participating consumers ultimately feel a certain obligation to actually purchase the respective product or service. If this is not the case, consumers who are not willing to go through the entire 


\section{PRE-PRINT VERSION}

Mladenow, Andreas, Bauer, Christine, \& Strauss, Christine (2016). Power to the (Shopping) People! Changing Traditional Customer-Vendor Interaction in Online Markets by ICT-Enabled “Group Buying”. In D'Ascenzo, Fabrizio, Magni, Massimo, Lazazzara, Alessandra, \& Za, Stefano (eds.), Blurring the Boundaries through Digital Innovation: Individual, Organizational, and Societal Challenges. Lecture Notes in Information Systems and Organisation (LNISO), Volume 19, pp 203-213. Cham, Switzerland: Springer. DOI: 10.1007/978-3-319-38974-5_16

This is a post-peer-review, pre-copyedit version of an article published in Blurring the Boundaries Through Digital Innovation, part of the Lecture Notes in Information Systems and Organisation book series (LNISO, volume 19). The final authenticated version is available online at: https://doi.org/10.1007/978-3-319-38974-5 16

crowd shopping process or who are not willing to buy a product or service will be carried through halfway of the process. Accordingly, in order to achieve a certain seriousness and commitment and to reduce the dropout rate of participants, one viable solution could, for instance, be to ask participants to state their credit card details. Furthermore, there is no income directly associated with the transactions involved when using the bottom-up approach of group buying. Similar to the top-down approach the offer has to be adapted to every market, which includes high evaluation and transaction costs. In addition, the bottom-up approach to group buying is currently not applicable in many countries. The low differentiation of platforms from competing ones is a weakness that the bottom-up approach shares with the top-down approach to group buying.

The opportunities for platforms using the bottom-up approach are similar to the ones for platforms applying a top-down approach. Investing in additional services, branding for suppliers, and investing in customer loyalty are among the opportunities with potentially the highest impact.

The threats for bottom-up approach platform providers are the tight competition and the low entry barriers into the market for new companies. The negative word-of-mouth is particularly threatening for this type of group shopping as consumers highly interact and bad reputation may spread as easily as positive experience and the invitation to participate.

\section{Discussion and Outlook}

'Group buying' as a term is not used consistently. One can find it in connection with grouponing as a marketing tool (top-down approach) as well as a bottom-up approach, where consumers that share the intent to purchase a specific product or service engage in forming buying groups. In the latter case a price reduction is achieved primarily by means of attaining a higher market share and - as a consequence - bargaining power. The common intent to purchase a product or service leads to a common interest within a community, which strives through the coordination and organization among the members to achieve their target of acquiring a product or service and thus to benefit from the cooperation. In addition to the described differences, both approaches serve the principle of benefiting from high accessibility thanks to the Internet. Thus, there is also the need for a sufficiently high number of interested people necessary for the implementation of both approaches. Furthermore, the two approaches are similar in terms of offering very time-limited deals. Different, however, are the initiators who act at the beginning of the group-buying approach.

Interestingly, the top-down platform concept with dynamic price level such as LetsBuyIt.com, Mobshop.com, and Mercata.com vanished; so did recent successor Jasmere.com. In this regard, this concept turned out as being too complicated for customers as the selected pricing strategy is based on the number of participating customers throughout the entire offer period. The more customers that accept the current price, the faster the next lower price level is reached. In this respect, customers have often not been aware of the currently valid price.

When it comes to group buying, the basic question is whether the new business model variant will be accepted or not; just as Mobshop.com was confronted with around the turn of the millennium. This question of acceptance includes the risk of not reaching a critical mass of customers at an early stage, which is required in order to implement the model successfully. In addition, a trustworthy and professional online appearance 


\section{PRE-PRINT VERSION}

Mladenow, Andreas, Bauer, Christine, \& Strauss, Christine (2016). Power to the (Shopping) People! Changing Traditional Customer-Vendor Interaction in Online Markets by ICT-Enabled “Group Buying”. In D'Ascenzo, Fabrizio, Magni, Massimo, Lazazzara, Alessandra, \& Za, Stefano (eds.), Blurring the Boundaries through Digital Innovation: Individual, Organizational, and Societal Challenges. Lecture Notes in Information Systems and Organisation (LNISO), Volume 19, pp 203-213. Cham, Switzerland: Springer. DOI: 10.1007/978-3-319-38974-5_16

This is a post-peer-review, pre-copyedit version of an article published in Blurring the Boundaries Through Digital Innovation, part of the Lecture Notes in Information Systems and Organisation book series (LNISO, volume 19). The final authenticated version is available online at: https://doi.org/10.1007/978-3-319-38974-5 16

is essential for the company. The aim is to build quickly a community of consumers who are willing to participate actively. Be it by participating in crowd shopping as buyers, or by contributing suggestions and ideas that will be later implemented by the company, or by participating in some other form. The exact business concept may vary depending on the offered products and services (or the companies in the B2B area). In this regard it is important to provide an appropriate combination or the most promising overall package of options and features, coupled with an efficient marketing campaign to catch attention.

Interestingly, while there has been a trend towards predefined vendor-initiated "daily deals" in countries such as the USA, in other countries, platforms such as China's market leader TeamBuy.com.cn, where forum members initiate crowd shopping activities, have flourished.

Overall, group buying allows companies to serve larger quantities of solvent customers, resulting in additional profit margins.

A disadvantage for participating companies arises from the increased influence of customers on pricing negotiations in a group buying setting [30, 31]. The bargaining power of customers is particularly strong in the bottom-up approach implementation of the group buying instrument. As a result, unit contribution margins may be lowered compared to traditional customer-vendor settings. To counteract lower margins, suppliers may set prerequisites in the price negotiations; for instance, a frequently used instrument is it to require a particular number of overall sales for granting a certain price. From the perspective of the supplier, determining the ideal group size is a major challenge, because quoting unrealistic sales volumes in negotiations will deter potential customers while asking for small group sizes may allow for lower profits only. If the required number of potential buyers has not yet been reached, consumers are typically motivated to distribute product information to other potentially people. The success for group buying, thus, depends largely on the efficiency of consumers as sales aids.

The fact that consumers may not know in advance which price they finally have to pay, the group buying approach with dynamic pricing mechanisms might turn out as too complex for consumers, which may result in a lack of consumer acceptance on a broader basis. Granting discounts for recommending other users to join a purchase on the platform may represent an incentive to (still) participate.

While small and medium-size enterprises (SMEs) show an increased interest in cooperating with the consumers [32, 33, 34], larger companies are frequently less willing to respond to consumer groups regarding pricing, sometimes due to image reasons. For smaller companies, though, group buying offers the possibility to attract the attention of a large number of consumers and build a positive reputation [35]. The strategy to engage in group projects buying also suits companies that are geographically isolated. Despite their remoteness they may build up a base of customers who value beneficial business relations more than vicinity. Providing localized offers, though, is one of the strengths of current platforms, which should not be underestimated in the implementation of group buying concepts.

The thorough analysis in our work provides a basis for explaining changes and developments of online group shopping variants and may contribute to the development and improvement of future business models.

As the types of group shopping vary tremendously with regard to communication, coordination, and collaboration among participants, a potentially interesting line of research would be the analysis of the various interaction requirements in the different group buying approaches The support of ICT in the different phases of the customer buying process would be a further interesting field of investigation, as ICT could help 


\section{PRE-PRINT VERSION}

Mladenow, Andreas, Bauer, Christine, \& Strauss, Christine (2016). Power to the (Shopping) People! Changing Traditional Customer-Vendor Interaction in Online Markets by ICT-Enabled “Group Buying”. In D'Ascenzo, Fabrizio, Magni, Massimo, Lazazzara, Alessandra, \& Za, Stefano (eds.), Blurring the Boundaries through Digital Innovation: Individual, Organizational, and Societal Challenges. Lecture Notes in Information Systems and Organisation (LNISO), Volume 19, pp 203-213. Cham, Switzerland: Springer. DOI: 10.1007/978-3-319-38974-5_16

This is a post-peer-review, pre-copyedit version of an article published in Blurring the Boundaries Through Digital Innovation, part of the Lecture Notes in Information Systems and Organisation book series (LNISO, volume 19). The final authenticated version is available online at: https://doi.org/10.1007/978-3-319-38974-5_16

to improve the involved shopping process and the underlying notion of the different business models.

\section{References}

1. Shin, D.H.: User experience in social commerce: in friends we trust. Behaviour \& Information Technology 32:1, pp. 52-67 (2013)

2. Wang, J. J., Zhao, X., \& Li, J. J.: Group buying: A strategic form of consumer collective. Journal of Retailing, 89(3), pp. 338-351 (2013)

3. Liu, Y., \& Sutanto, J. Online Group-Buying: Literature Review and Directions for Future Research. ACM SIGMIS Database, 46(1), pp. 39-59 (2015)

4. Luo, X., Andrews, M., Song, Y., \& Aspara, J. (2014). Group-buying deal popularity. Journal of Marketing, 78(2), pp. 20-33 (2014)

5. Mladenow, A., Bauer, C., \& Strauss, C., Collaborative Shopping with the Crowd. The 12th International Conference on Cooperative Design, Visualization \& Engineering. CDVE 2015, Mallorca, Spain, September 20-23. LNCS 9320. DOI: 10.1007/978-3-319-241326_19. Springer, pp. 162-169 (2015)

6. Jing, X., \& Xie, J.: Group buying: A new mechanism for selling through social interactions. Management Science, 57(8), pp. 1354-1372 (2011)

7. Lee, E.: 2013 China's Group-buying Turnover Rockets 67.7\% YOY to 35.88 Billion Yuan, http://technode.com/2014/01/15/2013-group-buying-turnover-rockets-68-percent-yoy-inchinal, accessed on November 22th (2015)

8. Chen, W. Y., \& Wu, P. H.: Factors affecting consumers' motivation in online group buyers. In Intelligent Information Hiding and Multimedia Signal Processing (IIH-MSP), 2010 Sixth International Conference on IEEE. pp. 708-711 (2010)

9. Kauffman, R. J., Lai, H., \& Ho, C. T.: Incentive mechanisms, fairness and participation in online group-buying auctions. Electronic Commerce Research and Applications, 9(3), pp. 249-262 (2010)

10. Chung, W., \& Chen, L.: Group-buying e-commerce in China. IT Professional, 14(4), pp. 2430. (2012).

11. Yu, M., Lang, K., \& Pelaez, A. Evaluating Electronix Market Designs: The Effects of Competitive Arousal and Social Facilitation on Electronic Group Buying. 47thHawaii International Conference on System Science. pp. 4148-4157 (2014)

12. Leitner, P., \& Grechenig, T.: Collaborative shopping networks: Sharing the wisdom of crowds in E-commerce environments. BLED 2008 Proceedings, 21 (2008)

13. Zhang, J. J., \& Tsai, W. H. S. United We Shop! Chinese Consumers' Online Group Buying. Journal of International Consumer Marketing, 27(1), pp. 54-68 (2015)

14. Edelman, B., Jaffe, S., \& Kominers, S. D.: To groupon or not to groupon: The profitability of deep discounts. Marketing Letters, pp. 1-15 (2011)

15. Dickinger, A., \& Kleijnen, M.: Coupons going wireless: Determinants of consumer intentions to redeem mobile coupons. Journal of Interactive Marketing, 22(3), pp. 23-39 (2008)

16. Sharif-Paghaleh, H.: Analysis of the Waiting Time effects on the Financial Return and the order fulfillment in web-based group buying mechanisms. In Proceedings of the 2009 IEEE/WIC/ACM International Joint Conference on Web Intelligence and Intelligent Agent Technology-Volume 01. IEEE Computer Society. pp. 663-666 (2009)

17. Tan, W. K., \& Tan, Y. J.: Online or offline group buying?. In 2010 Seventh International Conference on Fuzzy Systems and Knowledge Discovery (6), pp. 2853-2857 (2010)

18. Bauer, C., Mladenow, A., Strauss, C.: Fostering Collaboration by Location-Based Crowdsourcing. In Cooperative Design, Visualization, and Engineering: 11th International Conference, CDVE 2014, Seattle, WA, USA, September 14-17, 2014. Proceedings Vol. 8683, Springer, pp. 88-95 (2014) 


\section{PRE-PRINT VERSION}

Mladenow, Andreas, Bauer, Christine, \& Strauss, Christine (2016). Power to the (Shopping) People! Changing Traditional Customer-Vendor Interaction in Online Markets by ICT-Enabled “Group Buying”. In D'Ascenzo, Fabrizio, Magni, Massimo, Lazazzara, Alessandra, \& Za, Stefano (eds.), Blurring the Boundaries through Digital Innovation: Individual, Organizational, and Societal Challenges. Lecture Notes in Information Systems and Organisation (LNISO), Volume 19, pp 203-213. Cham, Switzerland: Springer. DOI: 10.1007/978-3-319-38974-5_16

This is a post-peer-review, pre-copyedit version of an article published in Blurring the Boundaries Through Digital Innovation, part of the Lecture Notes in Information Systems and Organisation book series (LNISO, volume 19). The final authenticated version is available online at: https://doi.org/10.1007/978-3-319-38974-5_16

19. Cho, N. \& Park, S.: Development of electronic commerce user-consumer satisfaction index (ECUSI) for Internet shopping, Industrial Management \& Data Systems, 101(8), pp.400406. (2001)

20. Liao, S. H., Chu, P. H., Chen, Y. J., \& Chang, C. C.: Mining customer knowledge for exploring online group buying behavior. Expert Systems with Applications, 39(3), pp. 37083716 (2012)

21. Hsu, M. H., Chang, C. M., Chu, K. K., \& Lee, Y. J.: Determinants of repurchase intention in online group-buying: The perspectives of DeLone \& McLean IS success model and trust. Computers in Human Behavior, 36, pp. 234-245 (2014)

22. Zhang, Z., Zhang, Z., Wang, F., Law, R., \& Li, D. (2013). Factors influencing the effectiveness of online group buying in the restaurant industry. International Journal of Hospitality Management, 35, pp. 237-245 (2013)

23. Blumenthals, http://blumenthals.com/blog/2014/03/05/google-shuts-down-self-serveoffers-product, accessed on November 22th (2015)

24. Forbes, http://www.forbes.com/sites/tomiogeron/2011/08/26/facebook-shutting-downdeals-service/, accessed on November 22th (2015)

25. Mladenow, A., Bauer, C., \& Strauss, C. Crowdsourcing in Logistics: Concepts and Applications Using the Social Crowd. DOI: 10.1145/2837185.2837242. Edition: ICPS International Conference Proceedings Series, Publisher: ACM, Editors: Indrawan-Santiago, Steinbauer, Khalil, Gabriele Anderst-Kotsis, pp.244-251 (2015)

26. Hyben, B., Mladenow, A., Novak, N.M., \& Strauss, C.: Consumer acceptance on mobile shopping of textile goods in Austria: modelling an empirical study; in The 13th International Conference on Advances in Mobile Computing and Multimedia (MoMM 2015), ACM, ISBN: 978-1-4503-3493-8; pp. 402 - 406 (2015)

27. Mladenow, A., Novak, N. M., \& Strauss, C.: Mobility for 'Immovables'-Clouds Supporting the Business with Real Estates. The 6th International Conference on Emerging Ubiquitous Systems and Pervasive Networks (EUSPN 2015). Procedia Computer Science, 63, pp. 120127 (2015)

28. Kopetzky, R., Günther, M., Kryvinska, N., Mladenow, A., Strauss, C., \& Stummer, C. (2013). Strategic management of disruptive technologies: a practical framework in the context of voice services and of computing towards the cloud. International Journal of Grid and Utility Computing, 4(1), pp. 47-59 (2013)

29. Mladenow, A., Bauer, C., Strauss, C., \& Gregus, M.: Collaboration and Locality in Crowdsourcing. DOI: 10.1109/INCoS.2015.74. In Intelligent Networking and Collaborative Systems (INCOS), 2015 International Conference on, pp. 1-6 (2015)

30. Xie, G., Zhu, J., Lu, Q., \& Xu, S.: Influencing factors of consumer intention towards web group buying. In Industrial Engineering and Engineering Management (IEEM), 2011 IEEE International Conference on IEEE. pp. 1397-1401 (2011)

31. Dickinger, A., \& Kleijnen, M.: Coupons going wireless: Determinants of consumer intentions to redeem mobile coupons. Journal of Interactive Marketing, 22(3), pp. 23-39 (2008)

32. Mladenow, A., Novak, N.M., \& Strauss, C.: Online Ad-Fraud in Search Engine Advertising Campaigns, Prevention, Detection and Damage Limitation. Information \& Communication Technology-Eurasia Conference ICT-EurAsia 2015, LNCS 9357. DOI: 10.1007/978-3-31924315-3_11. Springer, pp. 109-118 (2015)

33. Mladenow, A., Novak, N.M., \& Strauss, C.: Micropayments in virtuellen Welten Prozessmodell und Nutzung bei 7- bis 12-jährigen Besuchern. In GI-Edition: Informatik 2015, editors: Douglas Cunningham, Petra Hofstedt, Klaus Meer, Ingo Schmitt. 28.9-2.10. 2015, Cottbus. Lecture Notes in Informatics , pp. 1267-1278 (2015)

34. Mladenow, A., \& Fröschl, K.: Kooperative Forschung. Frankfurt am Main, Peter Lang (2011)

35. Tan, C. H., Goh, K. Y., \& Teo, H. H.: An investigation of online group-buying institution and buyer behavior. In Human-Computer Interaction. HCI Applications and Services. Springer, pp. 124-131 (2007) 